\title{
The Effect of Hydrogen-Charging on Mechanical Properties of Austenitic CrNi Steel Fabricated by Wire-Feed Electron Beam Additive Manufacturing
}

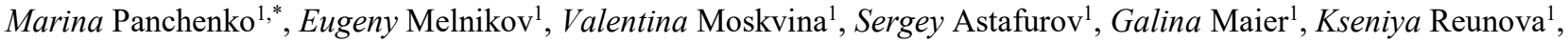 \\ Valery Rubtsov ${ }^{1}$, Evgeny Kolubaev ${ }^{1}$, and Elena Astafurova ${ }^{1}$ \\ ${ }^{1}$ Institute of Strength Physics and Materials Science, Siberian Branch of Russian Academy of Sciences, 634055, Akademicheskii pr., \\ 2/4, Tomsk, Russia
}

\begin{abstract}
A comparative study of the mechanical properties, fracture mechanisms and hydrogen embrittlement peculiarities was carried out using the specimens of austenitic CrNi steel produced by two different methods: wire-feed electron beam additive manufacturing and conventional casting followed by solid-solution treatment. Hydrogen-induced reduction of ductility and the increase in the yield strength are observed in steel specimens produced by both methods. Despite hydrogen embrittlement index is comparable in them, the increase in the yield strength after hydrogen-charging is different: $25 \mathrm{MPa}$ for cast steel and $175 \mathrm{MPa}$ for additively manufactured steel. This difference is associated with the peculiarities of phase composition and phase distribution in steels produced by different methods.
\end{abstract}

\section{Introduction}

Additive manufacturing (AM) is one of the developing areas of modern industry, it allows to create threedimensional products of the complex form and architecture based on a digital model. For the 3D printing of a metal component, a direct energy deposition (DED) method is one of the most promising technologies since it is characterized by high deposition rate and large work envelopes compared to other AM technologies (powder bed fusion (PBF) methods, and etc.) $[1,2]$. The layer-upon-layer strategy used in the DED method brings its own characteristics to the microstructure of the material that significantly affects its properties, including resistance against aggressive environments. Therefore, in order to create AM components suitable for different applications, a comprehensive study on the effect of the as-deposited unique microstructures on the material properties is necessary.

Austenitic stainless steel is the corrosion resistant material and is not susceptible to hydrogen embrittlement. This class of steels is widely used and is a promising material for AM due to its high operational properties (satisfactory mechanical properties, reliability, weldability and processability). There is a lot of data in the literature on the inhomogeneous, anisotropic structure of austenitic steel obtained by the AM methods. Wang et al. [3] have reported that laser-based DED AM 304L steel is characterized by the coarse columnar structure and by the significant anisotropy of mechanical properties, and such peculiarities are typical for austenitic steels fabricated by AM $[4,5]$. Due to rapid cooling and complex thermal history of the AM-billets, a $\delta$-ferrite is observed in AM austenitic steels [5-7]. Chen et al. [7] have pointed out that the brittle sigma phase arises in 316L stainless steel fabricated by gas metal arc AM. The complex inhomogeneous heterophase structure of AM austenitic steels leads to a change in their basic mechanical properties in comparison with conventional cast material [3-7].

This work is devoted to the comparative study of the effect of hydrogen-charging on mechanical properties and fracture mechanisms in wire-feed electron beam additively manufactured (EBAM) austenitic steel and conventional cast stainless steels.

\section{Materials and methods}

Austenitic stainless steel wire with a chemical composition Fe-19.1Cr-9.1Ni-0.95Si-0.12C (wt. \%) was used for wire-feed EBAM processing (EBAM steel). The EBAM process was conducted under beam acceleration voltage of $30 \mathrm{kV}$, scanning frequency $1 \mathrm{kHz}$, beam current $16.5 \mathrm{~mA}$, wire-feed rate $200 \mathrm{~mm} / \mathrm{min}$, ellipse scan $(4 \times 4 \mathrm{~mm})$ under vacuum condition. The EBAMbuilding was performed in layer-upon-layer strategy. A total of 30 parallel layers were deposited. As the reference material, the cast and solution-treated austenitic AISI 321 steel was used (further referenced as cast steel). Cast steel has the chemical composition: Fe17.4Cr-8.8Ni-1.1Mn-0.4Si-0.5Ti-0.07C (wt. \%).

The Altami MET 1C light microscope (LM) and a scanning electron microscope (SEM, Phillips SEM-515) equipped with energy dispersive X-ray spectrometer (EDS) were used to microstructural analyses. Specimens for tensile test with the final gauge section of $12 \mathrm{~mm}$

* Corresponding author: panchenko.marina4@gmail.com 
$\times 3 \mathrm{~mm} \times 0.9 \mathrm{~mm}$ (thickness) were prepared from the EBAM-built billet and the cast and solution-treated material. The principal axis of tensile specimens of EBAM steel was parallel to the building direction. The surface of the specimens was mechanically grinded and electrolytically polished.

Electrochemical $\mathrm{H}$-charging of the specimens was conducted for $50 \mathrm{~h}$ at the current density of $50 \mathrm{~mA} / \mathrm{cm}^{2}$ and room temperature, in $3 \% \mathrm{NaCl}$ water-solution. Immediately after $\mathrm{H}$-charging, the tensile tests to failure were conducted at room temperature and an initial strain rate of $5 \times 10^{-4} \mathrm{~s}^{-1}$ using an electromechanical machine LFM-125 (Walter+Bai AG).

\section{Results and Discussion}

\subsection{Microstructure characterization}

Fig. 1 shows typical microstructures in EBAM-built and convensional cast (and solution-treated) steel specimens.
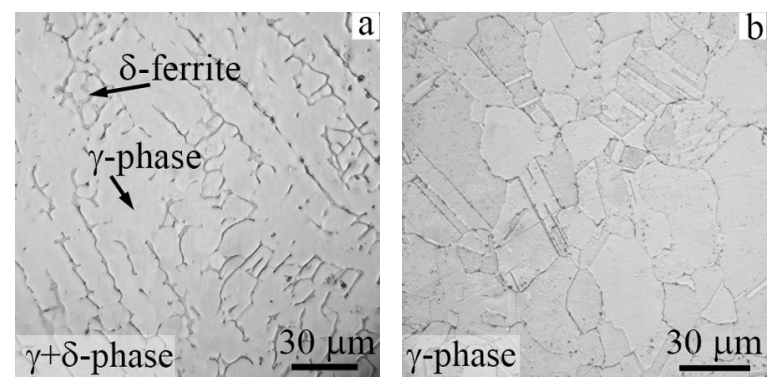

Fig. 1. LM images of EBAM-built (a) and conventional cast (b) specimens.

The EBAM steel exhibits columnar grain structure where grains are elongated along the building direction. In specimens of EBAM-built steel, the $\delta$-ferrite with a predominantly fine vermicular and lathy morphology in the $\gamma$-phase matrix is observed (Fig. 1a). The thickness of $\delta$-ferrite lamellae varies in the interval $0.5-1.5 \mu \mathrm{m}$. A full description of the grain structure and phase composition of this EBAM-fabricated steel can be found in our previous work [5]. The appearance of $\delta$-ferrite is associated with the variation in chemical composition of the wire during deposition ( $\mathrm{Ni}$ depletion) and the features of the EBAM process (thermal history and cooling rate). The solidification mode and morphology of austenite and ferrite in $\mathrm{Cr}-\mathrm{Ni}$ stainless steels is governed by the cooling rate and $\mathrm{Cr}_{\text {eq }} / \mathrm{Ni}_{\text {eq }}$ ratio [8] and, for our EBAM-produced steel, they have been earlier described in detail in [5].

In contrast to the EBAM-produced steel, the conventionally produced steel (casting + solution treatment) has single-phase coarse austenitic structure (Fig. 1b). The LM image of the etched surface of the cast steel specimen shows equiaxed coarse grains with an average size of $20 \mu \mathrm{m}$ and numerous annealing twins.

Therefore, specimens of two stainless steels obtained by the conventional casting and using AM method have different grain structures and phase compositions $(\gamma$ phase for the cast steel and $\gamma$-phase $+20-25 \% \delta$-ferrite for the EBAM-produced steel).

\subsection{Mechanical properties and fracture mechanisms}

The tensile engineering stress - engineering strain diagrams for $\mathrm{H}$-free and $\mathrm{H}$-charged specimens of the cast and EBAM-built steels are shown in Fig. 2. Table 1 contains data on mechanical properties of the specimens (a yield strength $\sigma_{0.2}$, an ultimate tensile stress $\sigma_{\text {UTS }}$, and a total elongation EL).
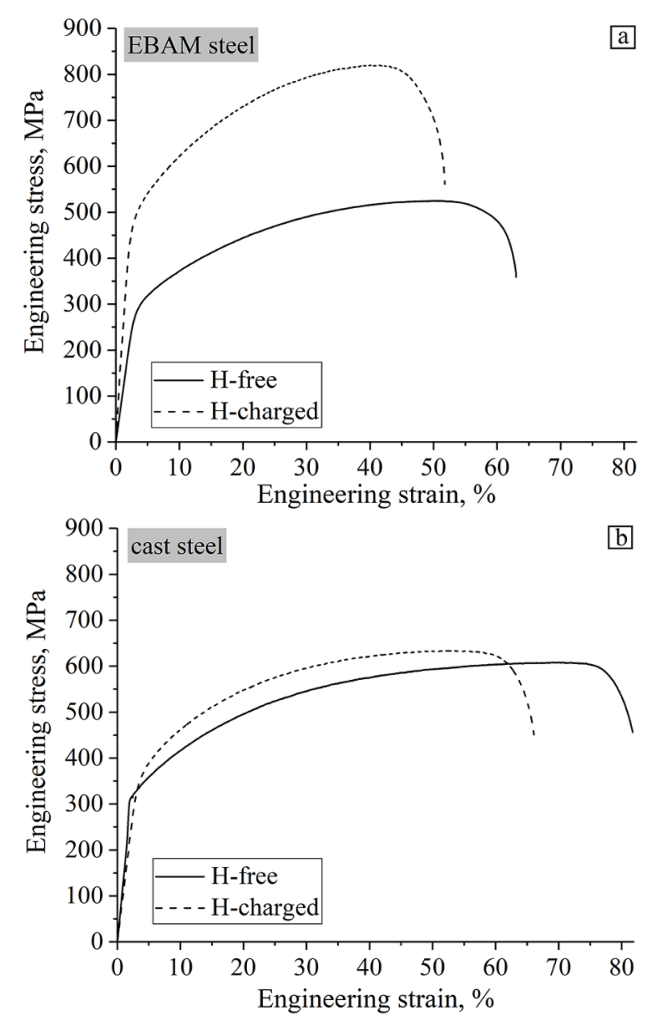

Fig. 2. Tensile engineering stress - engineering strain diagrams for $\mathrm{H}$-free and $\mathrm{H}$-charged EBAM-built (a) and cast (b) steels.

Table 1. Tensile properties of the EBAM-built and cast specimens before and after H-charging.

\begin{tabular}{|c|c|c|c|}
\hline Steel & $\sigma_{0.2, \mathrm{MPa}}$ & бUTs, MPa & EL, \% \\
\hline $\begin{array}{c}\text { H-free, } \\
\text { EBAM steel }\end{array}$ & 275 & 805 & 59 \\
\hline $\begin{array}{c}\text { H-charged, } \\
\text { EBAM steel }\end{array}$ & 450 & 1175 & 48 \\
\hline $\begin{array}{c}\text { H-free, } \\
\text { cast steel }\end{array}$ & 315 & 1050 & 79 \\
\hline $\begin{array}{c}\text { H-charged, } \\
\text { cast steel }\end{array}$ & 340 & 950 & 57 \\
\hline
\end{tabular}

The H-free specimens of both steels have mechanical characteristics typical for austenitic stainless steels. The decrease in stress and elongation to failure in EBAMfabricated specimen in comparison with cast one is caused by the complex heterogeneous $(\gamma+\delta)$ structure of the EBAM-built steel. Nevertheless, after AMfabrication without any additional treatments, the EBAM-produced steel has satisfactory mechanical properties comparable with cast material.

$\mathrm{H}$-charging causes a change in the mechanical properties of the specimens (Fig. 2). Hydrogen embrittlement is observed in both steels. The values of 
the hydrogen embrittlement index, which characterizes the relative hydrogen-induced loss in elongation, are $\mathrm{I}_{\mathrm{H}}=27 \%$ for the cast steel and $\mathrm{I}_{\mathrm{H}}=19 \%$ for the EBAM-fabricated one.

The yield strength increases in both steels under $\mathrm{H}$ charging but the $\mathrm{H}$-assisted $\sigma_{0.2}$-increment is higher for AM-fabricated specimens. In cast steel, the $\sigma_{0.2}$-value increases in $25 \mathrm{MPa}$ after $\mathrm{H}$-charging relative to the $\mathrm{H}$ free state. On the contrary, in the EBAM-fabricated specimens, the difference between the $\sigma_{0.2}$ for the $\mathrm{H}$-free and $\mathrm{H}$-charged states reaches $175 \mathrm{MPa}$. Such sharp increase in the yield strength could be associated with the specific $(\gamma+\delta)$ microstructure of the steel fabricated by the AM-method. Ferrite and austenite have different hydrogen diffusivity (it is higher in ferrite than in austenite) and different hydrogen solubility (ferrite possesses lower hydrogen solubility than austenite) [9]. Therefore, dendritic $\delta$-ferrite lamellae can act as continuous "pathway" that promote fast transport of hydrogen atoms deep into the specimens. Austenitic interdendritic areas between ferrite can effectively trap hydrogen atoms in the crystal lattice and, thereby, undergo solid solution hardening. The strong solid solution hardening of austenite by hydrogen atoms was previously reported for austenitic stainless steels in studies by D.P. Abraham and D.G. Ulmer with coauthors $[10,11]$. Fast hydrogen transport via dendritic $\delta$-ferrite in the EBAM-processed steel could provide both higher hydrogen content and deeper $\mathrm{H}$-assisted surface layers as compared to the cast steel (single-phase).
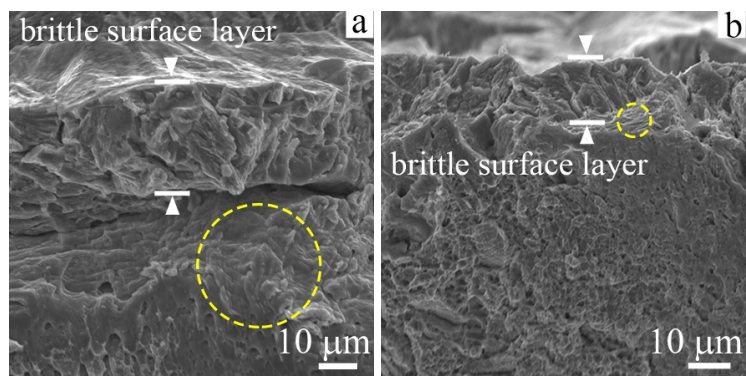

Fig. 3. SEM images of the fracture surfaces in H-charged specimens of the EBAM-built (a) and cast (b) steels (the deformation relief in subsurface areas are marked by circles).

SEM images of the fracture surfaces for H-charged specimens are presented in Fig. 3. Central parts of the $\mathrm{H}-$ charged specimens possess trangranular fracture mode with the formation of dimples on the fracture surfaces for both types of the steel. This fracture micromechanism is typical for austenitic stainless steels [12]. In both steels, $\mathrm{H}$-assisted brittle layers exhibit predominantly trangranular fracture mode (quasicleavage). The secondary cracking in the cast steel is visibly rarely than in the EBAM steel. In addition to the obvious brittle surface layer, a particular deformation relief is observed in subsurface regions (marked by a yellow circles line in Fig. 3), which testify a substantial plastic deformation after surface cracking. The depth of hydrogen-assisted layers in the EBAM steel is notedly larger than that in the cast steel: $30-35 \mu \mathrm{m}$ for the EBAM-fabricated specimen (Fig. 3a) and 12-17 $\mu \mathrm{m}$ for the cast one (Fig. 3b). Thus, the higher H-affected fraction of the materials, which is associated with faster transfer of hydrogen atoms in $(\gamma+\delta)$ microstructure, causes higher $\mathrm{H}$-assisted strengthening effects in AMfabricated steel in comparison with $\gamma$-phase cast one.

\section{Summary}

The effect of H-charging on the mechanical properties and fracture micromechanisms in EBAM-fabricated and cast $\mathrm{CrNi}$ austenitic steels was evaluated. Faster hydrogen transfer in $(\gamma+\delta)$ microstructure of the EBAMfabricated steel provides stronger $\mathrm{H}$-assisted hardening and higher hydrogen embrittlement relative to singlephase austenitic cast steel. Despite the heterogeneous structure, the EBAM-built austenite steel is characterized by relatively high resistance against hydrogen embrittlement, which is comparable with that in conventional austenitic stainless steels.

The work was performed according to the Government research assignment for ISPMS SB RAS, project No. III.23.2.7

\section{References}

1. T.D. Ngo, A. Kashani, G. Imbalzano, K.T.Q. Nguyen, D. Hui, Compos. Part B Eng. 143, 172-196 (2018)

2. L. Ron, G.K. Levy, O. Dolev, A. Leon, A. Shirizly, E. Aghion, Metals 9, 888 (2019)

3. Zh. Wang, T.A. Palmer, A.M. Beese, Acta Mater. 110, 226-235 (2016)

4. J. Yu, M. Rombouts, G. Maes, Mater. Des., 45, 228-235 (2013)

5. E.G.Astafurova, M.Yu. Panchenko, V.A. Moskvina, G.G. Maier, S.V. Astafurov, E.V. Melnikov, A.S. Fortuna, K.A. Reunova, V.E. Rubtsov, E.A. Kolubaev, J. Mater. Sci. 55, 9211-9224 (2020)

6. S.Yu. Tarasov, A.V. Filippov, N.N. Shamarin, S.V. Fortuna, G.G. Maier, E.A. Kolubaev, J. Alloys Compd. 803, 364-370 (2019)

7. X. Chen, J. Li, X. Cheng, B. He, H. Wang, Zh. Huang, Mater. Sci. Eng. A 703, 567-577 (2017)

8. W. Elmer, S.M. Allen, T.W. Eagar, Metall. Trans. A 20, 2117-2131 (1989)

9. X.Z. Liang, G.-H. Zhao, M.F. Dodge, T.L. Lee, H.B. Dong, P.E.J. Rivera-Díaz-del-Castillo, Materialia 9, 100524 (2020)

10. D.P. Abraham, C.J. Altstetter, MMTA 26A, 28492858 (1995)

11. D.G. Ulmer, C.J. Altstetter, Acta metal. mater. 41, 2235-2241 (1993)

12. E.G. Astafurova, E.V. Melnikov, S.V. Astafurov, I.V. Ratochka, I.P. Mishin, G.G. Maier, V.A. Moskvina, G.N. Zakharov, A.I. Smirnov, V.A. Bataev, Phys. Mesomech. 22, 313-326 (2019) 